\title{
THE ORIGINS OF THE STALINGRAD VICTORY: PSYCHOLOGICAL ASPECT
}

\author{
Aleksandr L. Strizoe \\ Volgograd State University, Volgograd, Russian Federation
}

\begin{abstract}
Introduction. The article points out the need for a special study of psychological aspects of the reasons for the victory of the Red Army at Stalingrad, which for a long time remained undervalued due to the traditional attention of researchers paid to the role of ideological factors. These aspects are revealed in the process of radical change in the moods of soldiers and commanders of the Red Army in the period between the issuance of Order No. 227 in July 1942 and the formation of new urban combat tactics in the winter of 1942-1943. The author notes the need to evaluate measures of command and practices of soldiers' and commanders' behaviour in war, taking into account the achievements of modern psychology. Methods. The author presents a methodological scheme for analysing the process of changing moods, the transition from confusion and panic to the formation of readiness for active defence and attack. Its elements include studying adaptation to the everyday difficulties of war, interpersonal trust and rational organization of various aspects of life in war as prerequisites for a psychological break in the moods of soldiers and commanders. Analysis and results. The article emphasizes the role of formation of self-organization and liberation of personal initiative of soldiers as one of the manifestations of positive psychological changes. These changes are conceptualized in a new understanding of courage. Along with the 'courage of self-sacrifice' characteristic of archaic culture and traditional society, the 'courage of self-affirmation', which is rooted in the values of the Renaissance and the early modern period and focused on success in military confrontation and preservation of the lives of soldiers and commanders, arises and spreads. The emergence and spread of new psychological attitudes and orientations during the Stalingrad battle can be assessed as the beginning of moral and psychological break in the Red Army, the beginning of the formation of the 'psychology of victory' as a powerful mobilizing factor.

Key words: The Battle of Stalingrad, psychological factors of victory, courage, self-sacrifice, self-affirmation, adaptation, trust, rational organization.

Citation. Strizoe A.L. The Origins of the Stalingrad Victory: Psychological Aspect. Vestnik Volgogradskogo gosudarstvennogo universiteta. Seriya 4, Istoriya. Regionovedenie. Mezhdunarodnye otnosheniya [Science Journal of Volgograd State University. History. Area Studies. International Relations], 2019, vol. 24, no. 1, pp. 155-164. (in Russian). DOI: https://doi.org/10.15688/jvolsu4.2019.1.13
\end{abstract}

УДК 94(47+57)«1942/1943»:930.2

Дата поступления статьи: 18.11 .18

ББК 63.3(2)622,12

Дата принятия статьи: 12.12 .18

\section{ИСТОКИ СТАЛИНГРАДСКОЙ ПОБЕДЫ: ПСИХОЛОГИЧЕСКИЙ АСПЕКТ}

\author{
Александр Леонидович Стризое \\ Волгоградский государственный университет, г. Волгоград, Российская Федерация
}

\footnotetext{
Аннотация. Статья указывает на необходимость специального исследования психологических аспектов причин победы Красной армии под Сталинградом, которые долгое время оставались недооцененными ввиду традиционного внимания исследователей к роли идеологических факторов. Эти аспекты выявляются в гі процессе кардинального изменения в настроениях бойцов и командиров Красной армии в период между $\gtrless$ изданием приказа № 227 в июле 1942 г. и формированием новой тактики городских боев зимой 1942-1943 годов. Автор отмечает необходимость оценки мер командования и практик поведения бойцов и командиров на войне с учетом достижений современной психологии. Он представляет методологическую схему анализа процесса смены настроений, перехода от растерянности и паники к формированию готовности к активной обороне и наступлению. Элементами ее являются изучение адаптации к повседневным трудностям войны,
} 
межличностного доверия и рациональной организации разных сторон жизни на войне как предпосылок психологического перелома в настроениях солдат и командиров. В статье подчеркнута роль становления самоорганизации и раскрепощения личной инициативы солдат как одного из проявлений позитивных психологических изменений. Эти изменения концептуализируются в новом понимании мужества. Наряду с «мужеством самопожертвования», характерным для архаической культуры и традиционного общества, возникает и распространяется «мужество самоутверждения», которое коренится в ценностях эпохи Возрождения и Нового времени и ориентировано на успех в военном противоборстве и сохранение жизни солдат и командиров. Появление и распространение в период Сталинградской битвы новых психологических установок и ориентаций может быть оценено как начало морально-психологического перелома в рядах Красной армии, начало формирования «психологии победы» как мощного мобилизующего фактора.

Ключевые слова: Сталинградская битва, психологические факторы победы, мужество, самопожертвование, самоутверждение, адаптация, доверие, рациональная организация.

Цитирование. Стризое А. Л. Истоки сталинградской победы: психологический аспект // Вестник Волгоградского государственного университета. Серия 4, История. Регионоведение. Международные отношения. - 2019. - Т. 24, № 1. - С. 155-164. - DOI: https://doi.org/10.15688/jvolsu4.2019.1.13

Введение. Значение Сталинградской битвы, ее итоги и уроки давно находятся в фокусе внимания отечественных и зарубежных историков. Сегодня многие стороны этого ключевого события Второй мировой войны стали предметом критического анализа, корректируются оценки отдельных эпизодов и действия участников событий, вводятся в оборот новые источники, выявляются новые аспекты анализа. Один из таких аспектов - психологический, его роль в методологии исследования военного противоборства, развернувшегося в $1942-$ 1943 гг. в Сталинграде, является предметом рассмотрения данной статьи.

В нынешнюю эпоху концептуального плюрализма в исторических исследованиях большинство общих оценок Сталинградского сражения не отрицают его значения как качественно нового этапа Великой Отечественной войны. Как отмечает А.В. Исаев, «перелом в войне вещь трудноформализуемая. Тем не менее можно сказать, что Сталинград является одним из переломных моментов войны» [7, с. 523]. Логично предположить, что наряду с собственно военными, технологическими, экономическими, политическими, морально-идеологическими факторами в этом переломе немалую роль сыграл психологический фактор.

Методы. Традиция советской историографии отождествлять субъективный фактор исторического процесса с сознанием его участников, а это последнее лишь с рациональноидеологическим содержанием приводило к замалчиванию и недооценке роли психологических компонентов сознания, определявших дей- ствия людей, тех сдвигов, которые происходили в этой сфере. Инерция этого подхода дает о себе знать и в сравнительно недавних работах. Так, Г.А. Куманев, рассматривая итоги, последствия и уроки Сталинградской битвы и отмечая, что духовный фактор «во многом обеспечил перелом в войне», фактически сводил его к ценности патриотизма и высокому моральному духу, который стал следствием «огромной партийно-политической, воспитательной и патриотической работы» в войсках [9, с.120]. Правда, теперь, повинуясь веяниям времени, автор признавал духоподъемный вклад не только партийных и комсомольских органов, но и Русской Православной Церкви. «Идеологический крен» прослеживается и в трактовке победы под Сталинградом немецкими историками. Оценивая сборник «Сталинградская битва. Свидетельства участников и очевидцев. По материалам Комиссии по истории Великой Отечественной войны», вышедший сравнительно недавно под редакцией Й. Хелльбека [16], В. Максаков пишет о трактовке авторами истоков Сталинградской победы: «Их ответ может в чем-то показаться неожиданным: сила духа, по их мнению, оказалась решающим фактором. А пытаясь объяснить эту последнюю, они и приходят к выводу о крайне важной роли коммунистической агитации и пропаганды, осознанной идеологии» [10]. Но любая рациональная идеология и пропаганда будут действенны, если ложатся на соответствующий им образный слой сознания, эмоциональный фон, подсознательные установки индивидов и групп. 
Даже в мемуарной литературе, по законам жанра тяготеющей к личностно-персонифицированному повествованию о прошлом, психологические стороны войны не получили должного отражения. Неслучайно один из участников войны, сражавшийся в Сталинграде, впоследствии священник и ученый, Г.А. Каледа писал о мемуарах наших полководцев: «...я не видел в них самого главного - психологии солдатских масс, ее изменения в ходе войны и влияния ее на исход сражений» [2]. Ликвидация этого «белого пятна» в наших исследованиях Великой Отечественной войны связана с появлением работ Е.С. Сенявской по историческим вопросам военной психологии $[14 ; 15]$. Однако обнаружение новых смысловых горизонтов, раскрытие процесса формирования, места и роли «психологии победы» у командиров и рядовых участников войны 1941-1945 гг. требует специального изучения отдельных, в том числе ключевых ее ситуаций и эпизодов. При таком исследовании неизбежно сопоставление отдельных фактов и эпизодов Сталинградской битвы с теоретическими конструктами современной психологии при помощи дедуктивно-номологических объяснений, феноменологических описаний и индуктивных обобщений.

Анализ. В чем состоит психологический аспект сталинградского перелома? А. Мерцалов полагал, что «перелом - это создание решающего и необратимого преимущества перед противником в экономической, политической, моральной, психологической, чисто военной областях с целью захвата инициативы и обеспечения победы» [11]. Применительно к состоянию сознания человека описание таких преимуществ вряд ли является проблемой. Обилие разнообразных исторических нарративов о событиях под Сталинградом позволяет сравнительно легко реконструировать мысли, эмоции, чувства и солдат, и полководцев. Гораздо более сложен анализ процесса перехода от «психологии поражения» к «психологии победы», вытеснения старых стереотипов и установок и замещения их новыми, имеющими принципиально иную направленность. Необратимость такого психологического фактора может быть гарантирована лишь его способностью воплощаться в конкретные действия, удерживающие инициативу в веде- нии войны, проявленную ранее, в том числе в Сталинграде.

Для моделирования процесса перехода от «психологии поражения» к «психологии победы» возьмем две хронологические точки: июль и сентябрь 1942 года. Они описывают переход от низшей точки падения боевого духа и армейской дисциплины, потребовавшей вмешательства Верховного главнокомандующего, до момента, когда задача выжить и победить была открыто артикулирована бойцами и командирами на передовой. Документально эти точки представлены, с одной стороны, известным приказом № 227 от 28 июля, а с другой - протоколом комсомольского собрания одной из стрелковых рот 308 дивизии 62 армии, запечатленным на одной из «стен-руин» памятника-ансамбля Мамаев курган, в мемуapax В.И. Чуйкова и многих других источниках. В действительности такой переход развивался нелинейно: шел в разных формах и с различной скоростью, меняя свои хронологические рамки на разных участках фронта. Г.А. Куманев описывал ситуацию, когда в приказе от 1 ноября 1942 г. командующий Донским фронтом генерал К.К. Рокоссовский с большой тревогой отмечал, что «дисциплина во всех частях продолжает оставаться на крайне низком уровне, вследствие чего командиры оказались не в состоянии в нужный момент поднять и направить в атаку свои части и подразделения» [9, с. 134]. Командующий был вынужден продвинуть вплотную к переднему краю заградотряды, чтобы поднять пехоту в атаку [20, с. 90-91].

В нашей литературе давались различные оценки как самому приказу № 227, так и его воздействию на армию и общество в годы войны. Для понимания его содержания и последствий важным, на наш взгляд, является психологический подход. Летом 1942 г. на сталинградском и кавказском направлениях, как и в 1941 г., обнаружилось предельное проявление утраты воинской дисциплины, растерянности и потери управления - паника. Паническая толпа, являясь одной из форм действующей толпы, в своем поведении может быть более опасной и разрушительной, чем то, что ее спровоцировало [12, с. 39]. При этом превращаемость, как основное свойство толпы, проявляется в том, что она может быстро и 


\section{ОТЕЧЕСТВЕННАЯ ИСТОРИЯ}

непредсказуемо менять свои состояния, что вдвойне опасно в условиях военного времени. Воздействие на паническую толпу требует выбора особого психологического момента, создания ситуации, когда толпа на короткое время останавливается, прекращает свое движение, застывает в оцепенении и становится открытой рациональному управлению и организации [12, с. 74, 82-83]. Среди приемов ликвидации паники известен и такой, как применение более сильного шокового воздействия. Как отмечает А.П. Назаретян, выстрел в закрытом помещении способен утихомирить разбушевавшуюся толпу. Иная ситуация на фронте, когда «во время боя, в шуме каннонады выстрел едва ли произведет желаемый эффект. Его может заменить внезапная стрельба в упор по своим убегающим солдатам...» [12, с. 83]. В случае массовых беспорядков движущаяся толпа может быть остановлена только вооруженной силой. Применение силы, таким образом, является неизбежным в подобных случаях. Его главной психологической целью является пресечение паники и восстановление боевых порядков войск.

Практика реализации приказа № 227 в период Сталинградской битвы еще ждет своего подробного исследования. Сами военные историки признавали его обоснованность. Так, М. Гареев писал: «...после поражений и больших потерь в мае - июне 1942 года было немало случаев растерянности и паники... Для психологического перелома в войсках нужна была серьезная встряска. И в этом отношении в целом положительную, на мой взгляд, роль сыграл приказ наркома обороны № 227, дававший острую и правдивую оценку обстановки и пронизанный главным требованием “Ни шагу назад!”» [4, с. 81]. Формы силового воздействия представителей НКВД на отдельных людей, как показывает анализ документов В.С. Христофоровым, в большинстве своем не были крайними. Что же касается воздействия на отдельные воинские подразделения, то и здесь достаточно примеров того, как заградотряды останавливали бегущие войска и восстанавливали рубежи обороны [20, c. 88-89], то есть достигали главной с психологической точки зрения цели шокового воздействия. Понятно, что реальность войны далеко не всегда соответствовала теоретичес- ки ожидаемым результатам, но из этого не следует делать вывод об абсурдности и необоснованности чрезвычайных мер.

Противодействие панике, ее пресечение есть лишь начало процесса отказа от «психологии поражения». Его завершение предполагает появление новых позитивно-оптимистических ориентиров в действиях, вытеснение неизбежного для военных испытаний фатализма смерти и даже героизма всеобщего и неотвратимого самопожертвования героизмом самоутверждения победителя. Движение к этим принципиально новым ценностно-психологическим ориентирам отражено в протоколе комсомольского собрания воинов 308 дивизии 62 армии. Документ фиксирует готовность бойцов к самопожертвованию: «В окопе лучше умереть, но не уйти с позором. И не только самому не уйти, но сделать так, чтобы и сосед не ушел». Ответ комсорга на вопрос об уважительных причинах ухода с огневой позиции гласил: «Из всех оправдательных причин только одна будет приниматься во внимание - смерть» [21, с. 211]. Но, закрывая собрание ввиду начавшейся двенадцатой за день атаки противника, командир роты высказал свою позицию: «Я должен внести некоторую ясность в выступление комсорга. Он много говорил здесь о смерти и сказал, что Родина требует от нас смерти во имя победы. Он, конечно, неточно выразился. Родина требует от нас победы, а не смерти. Да, кое-кто не вернется живым с поля боя - на то и война. Герой тот, кто умно и храбро умер, приблизив час победы. Но дважды герой тот, кто сумел победить врага и остался жив!» [21, с. 211]. В этой позиции важно отметить не только призыв к умелой обороне, стойкости и мужеству самопожертвования, но и смещение акцента в ценностных приоритетах: самопожертвование и смерть за Родину в словах командира роты выступают не как безусловная высшая цель красноармейца на войне, а как одно из средств достижения победы. Другим таким средством, причем не менее значимым, выступает сохранение жизни бойца для дальнейшего продолжения борьбы с врагом.

В основании этой новой расстановки приоритетов лежит изменение человеческого самосознания, взгляда на природу и предназначение человека, зафиксированное в свое вре- 
мя философией как различие между античным и возрожденческим, а следовательно и новоевропейским гуманизмом. «Решающее различие между двумя типами гуманизма, - пишет П. Тиллих, - заключено в ответе на вопрос: хорошо или плохо бытие само по себе? ...возрождение дало начало движению, обращенному к будущему, к творческому и новому в нем. Надежда победила чувство трагедии, а вера в прогресс - смирение перед вечно повторяющимся движением по кругу» [17, с. 19]. Одновременно в противовес традиционному обществу Возрождение и Новое время увидели в человеке неповторимую, самоценную своими творческими способностями и порывами свободы индивидуальность, самореализация которой и лежит в основании самоутверждения. Это самоутверждение, включающее в себя не только духовное, но и материальное, историческое, индивидуальное существование, отвергает, по П. Тиллиху, идею спасения и отречения от мирских благ.

Для нас принципиально важно то, что различие двух пониманий гуманизма связывается П. Тиллихом с появлением новой, просвещенческой по сути дела, трактовки мужества, приходящей на смену архаическитрадиционному пониманию мужества как самопожертвования. Представляя ее на примере философии Спинозы, П. Тиллих приводит его определение мужества. «Под мужеством, - пишет Спиноза, - я понимаю желание (cupiditas), с которым каждый человек стремится сохранить собственное бытие, руководствуясь исключительно указаниями разума» $[17$, с. 20$]$. Не будем подчеркивать излишнее упование рационалиста XVII в. на самосохранительную силу указаний разума. Гораздо важнее то, что добродетель и сила самоутверждения для Спинозы совпадали и предполагали благожелательное служение другим [17, с. 21]. Это превращало мужество самоутверждения на войне в силу, спасающую Отечество, завоевания цивилизации и культуры, а потому в силу жизни, преодолевающую смерть. Как пишет П. Тиллих, «мужество есть самоутверждение “несмотря на", т. е. вопреки тому, что стремится не дать Я утвердить себя» $[17$, с. 26]. Таким образом, Возрождение и Новое время формировали идеал «мужества жизни» активного, со- циального самоутверждения, противостоявший мужеству самопожертвования как «мужеству смерти».

Биологи утверждают, что в онтогенезе кратко, в свернутом виде повторяется филогенез. В нашем случае речь идет о том, что, как некогда во всемирной истории, в сознании и действиях единичного человека на войне по мере накопления военного опыта возникает потребность преодолеть безысходность солдатской судьбы, трагический круговорот военного бытия и происходит драматическое переживание этого преодоления. В этом переживании рождается мотивация, мобилизующая силы самосохранения и самоутверждения, органически связанная с верой в успех своего правого дела, в победу. Позитивная мотивация сознания и поведения, о возникновении которой мы говорим, связана с мобилизацией творческого разума, инициативы, изобретательности, возвышающих человека, а вместе с ним и жизнь над трагедией и смертью. Представляется, что эта мотивация и связанное с ней понимание мужества обладают очевидными преимуществами по сравнению с традиционным мужеством самопожертвования, которое веками культивировалось во всех армиях мира. Германская армия не представляла здесь исключения. Так, в пособии 1935 г. «Офицер ВМФ как командир и воспитатель», в частности, говорилось: «Лучшей наградой для офицера будет тот момент, когда неуверенность и страх исчезнут из глаз его людей и во взглядах, направленных на него, он будет читать только древний вопрос высшей степени доверия: “Где ты прикажешь нам умереть?”» [19, с. 335]. Применительно к 1942 г. и в особенности к Сталинградской битве формирование у солдат Вермахта мотивации «мужества жизни» как стремления своими усилиями приблизить победу становилось все более проблемным, поскольку реальность войны постепенно, но неуклонно убеждала их в ее ошибочности и бесперспективности.

Процесс психологического перелома, приводящий в итоге к новым установкам и ориентациям сражающихся армий, начинается с преодоления страха, с усилия над самим собой. Деморализующее воздействие страха связано с возникновением состояния паралича воли, апатии, безразличия, неспособности 
к активным действиям. Этот момент выразил Ф.Д. Рузвельт в одном из своих обращений к американцам в период великого кризиса 1929-1933 гг.: «Единственное, чего мы должны бояться, - это самого страха, безымянного, бессмысленного, безотчетного страха, который парализует усилия, необходимые для превращения отхода в наступление...» (выделено мной. - А. С.) [18, с. 109-110]. Такая способность к активным действиям, к эффективному противостоянию натиску врага формируется лишь по мере накопления на войне позитивного опыта выживания, преодоления трудностей и испытаний. Элементами этого опыта, по нашему мнению, являются, во-первых, адаптация к военной повседневности; во-вторых, возникновение и укрепление доверия бойцов друг к другу, а также бойцов и командиров; в-третьих, рационализация поведения в бою и самостоятельное решение задач в сложных и нестандартных условиях.

Важнейшим элементом психологической адаптации является формирование у человека на войне автоматизмов поведения, привычек реагировать на повседневные условия фронтовой жизни. Описывая мужество и храбрость как черты солдата, один из немецких военных психологов отмечал: «Мы не упускаем при этом из виду, что кроме нравственной основы храбрости у нее должна быть и функциональная основа. В повседневной жизни мы называем ее самообладанием. Это качество может усилить привычка к опасности разного рода... Но к опасности войны можно привыкнуть только на войне» [19, с. 277]. Стойкость к испытаниям войны, привычка к опасностям военного времени невозможны без самоконтроля, самоорганизации, ответственности за себя и товарищей. Эту сторону адаптации, связанную с личностной зрелостью и житейской мудростью, отмечал в свое время К. Симонов: «Жизненный опыт, добытый годами войны, чем-то очень существенно отличается от всякого другого жизненного опыта. Молодые люди тогда взрослели (я имею в виду духовную сторону этого понятия) за год, за месяц, даже за один бой» [3, с. 147]. Важным моментом адаптации является укрепление у бойцов и командиров уверенности в себе, в своей способности одолеть противника на поле брани. Момент становления такой внут- ренней убежденности описан в воспоминаниях Г.А. Каледы об одном из эпизодов солдатского быта: «...чистили картошку, разговаривали. ...и мне задают вопрос: “А ты думаешь - мы победим?”. Я говорю: “А давайте подумаем: в сентябре было легче, чем в августе? Да, а в октябре легче, чем в сентябре, в ноябре - легче, чем в октябре. Следовательно, у немцев силы-то иссякают, это мы чувствуем. А значит, мы можем накопить силы и по немцу ударить"» [13]. Отмеченное ощущение «нам стало легче» по сути дела означает, что бойцы не просто адекватно отвечают на «вызовы» фронтовой повседневности, а отвечают быстрее, опережая их появление, перехватывая инициативу у судьбы.

Адаптация человека на передовой не только сказывается на его самочувствии, придает ему оптимистическую окраску, но и проявляется в способности уверенно взаимодействовать со своим окружением, боевыми товарищами, выстраивать предсказуемые и устойчивые отношения с ними. Эти отношения невозможны вне климата доверия - важнейшей основы армейского коллективизма. В условиях интенсивных боевых действий, насыщенности фронтовой жизни разнообразными инженерными, материально-техническими, хозяйственными и иными работами, успешно выполнить которые возможно лишь сообща, многообразные личные качества людей, их достоинства, недостатки и слабости не только быстро выявляются в общении, но и столь же быстро и неизбежно должны согласовываться, приспосабливаться к обстоятельствам, подчиняться необходимости. Открытость в общении и личное доверие как черты характера человека на войне являются не только условием выживания. В отношениях людей они проявляются более глубоко: как взаимовыручка, единство в испытаниях, товарищество, знаменитые фронтовая дружба и братство. Эти отношения в наибольшей мере ощущались на микросоциальном уровне, в жизни таких воинских подразделений и коллективов, как взводы, расчеты, экипажи, роты, батареи, прежде всего, в дивизиях, оборонявших центр Сталинграда и прижатых к Волге. Без доверия было бы невозможно создание малых штурмовых групп, действие которых обеспечивали бойцы разных воинских специ- 
альностей, а также овладение новыми приемами боя в городских условиях. Многочисленные мемуары и произведения В. Некрасова, К. Симонова, Ю. Бондарева, посвященные Сталинградской битве, дают нам множество описаний непростых ситуаций фронтовой жизни и коллизий человеческих отношений, разрешавшихся на основе взаимной поддержки, доверия и ответственности. Уверенность в товарищах и командирах, находящихся рядом, в окопах, убежденность в том, что они не оставят занимаемые позиции, предотвращали крайние проявления дезорганизации и растерянности, которые ушли в прошлое к осени 1942 года.

В атмосфере взаимной психологической надежности возникали благоприятные условия для рационального, трезвого и спокойного самоанализа, оценки обстановки, организации собственных действий. Именно в возрастании роли рациональных компонентов сознания в оценке войны и своего места в ней проявилась новая психология солдат и командиров, психология уверенности в своих силах, в преимуществе над противником, в осознанном стремлении к успеху в бою. Оценивая бои в городе осенью 1942 г., В.И. Чуйков отмечал: «Сила наших гвардейцев была в том, что они дрались умело, расчетливо, стараясь с максимальным эффектом использовать оружие...» $[21$, c. 212$]$.

Это умение возникало не только стихийно, по мере накопления опыта, но было результатом сознательного тактического творчества и целенаправленного обучения бойцов. Известно, что Политуправление Сталинградского фронта при участии командарма В.И. Чуйкова выпустило брошюру «Из опыта уличных боев», посвященную тактике малых штурмовых групп [6]. На примере штурма «Дома железнодорожников» в ней детально рассматриваются структура и взаимодействие атакующих сил, разделенных на несколько групп и обеспеченных поддержкой 82 бойцов «самых различных воинских специальностей с применением различного оружия». При этом самое пристальное внимание уделяется времени, внезапности и тактике действий, их инженерной подготовке, обучению бойцов на местности, их психологическому настрою, работе с пополнением.
Показательно, что тщательная подготовка и планирование боевых действий дополняются требованием творческого подхода к решению поставленных задач. В.И. Чуйков писал: «Нужно каждому командиру следить за новым, подмечать это новое. Воспитание инициативы и дерзости - вот за что мы должны уцепиться сейчас, чтобы непрестанно наращивать грозную силу штурмовой группы» [6].

Отметим, что описанная в брошюре тактика касается не обороны, а наступления. Вопреки сложившимся стереотипам оборонительные бои, подобные обороне «дома Павлова», не являются типичными и наиболее распространенными формами борьбы в городе. Как отмечает А.В. Исаев, «едва ли не чаще советским частям приходилось самим атаковать занятые немцами здания. Происходило это либо с целью восстановления положения, либо с целью отбить господствующие над местностью пункты» [7, с. 420]. Эффективность подобного тактического планирования и обучения войск в период упорных позиционных боев достаточно высоко оценил противник. Беседуя в госпитале с ранеными немецкими солдатами, полковник В. Адам услышал следующее признание: «Здесь ничего нельзя добиться бешеной атакой напролом. Скорее сложишь голову. Мы должны научиться вести штыковой бой <..> этому надо учиться у русских. Они мастера уличного боя, умеют использовать каждую груду камней. Каждый выступ в стене, каждый подвал. Этого я от них не ожидал!» [1, с. 125]. Превосходство Красной армии в городском бою, в использовании местности и маскировке отмечали и немецкие генералы.

Важнейшим результатом рационального анализа ситуаций боя, собственных действий и действий противника является раскрепощение инициативы рядовых бойцов и командиров, развитие находчивости, смекалки, изобретательности. Неслучайно мнение одного из командиров 62 армии Н. Крылова, зафиксированное мемуаристом: «В городских боях каждый командир сам себе и командарм, а каждый солдат - сам себе командир! Нужна мгновенная ориентировка на месте, атака, контратака, обходное движение, отход, чтобы обойти то или иное здание» [5]. Эта установка на активность, самостоятельное принятие 
решений диаметрально противоположна параличу сознания и воли бойца, переживающего страх, апатии бездействия и безразличия, пассивному ожиданию приказов свыше. В ней раскрываются не только потенциал личностного роста и психологические преимущества российского солдата, но и результат психологического перелома, произошедшего под Сталинградом и сыгравшего огромную роль в обеспечении победы в войне.

Следует особо подчеркнуть роль не раз описанного мемуаристами и исследователями феномена пробуждения в человеке на войне творческого начала, чувства самоуважения, достоинства, духа самоорганизации и демократизма. Эти факты опровергают надуманные оценки морально-психологического облика солдат Красной армии, рисующие их почти как «недочеловеков» по сравнению с «цивилизованными» захватчиками. Так, в двухтомнике под редакцией А.Б. Зубова, посвященном отечественной истории XX в., утверждается: «Немецкий солдат был хозяйственным крестьянином-фермером или горожанином - активным, хорошо образованным, инициативным. Безликая масса красноармейцев состояла из забитых и замученных беспросветной жизнью пассивных колхозников. Командиры и генералитет РККА преимущественно происходили из социальных низов старой России, с низким уровнем образования и культуры» [8, с. 39]. Движимые пафосом обличения сталинского тоталитаризма и дискредитации социалистического проекта авторы не просто извращают действительность, отрицая деструктивное антигуманное воздействие идеологии и пропаганды фашизма на немецкий народ и в духе примитивных идеологических штампов изображая облик воинов Красной армии. Позиционируя эти характеристики как «вечные» культурно-цивилизационные константы (передовая Европа и дикая, отсталая Россия), они фактически отрицают шансы культурного и личностного роста рядовых и командиров РККА, возможность проявления у них высоких человеческих качеств и творческих способностей.

Выводы. Обращение к реальному, а не мифологизированному опыту Великой Отечественной войны и Сталинградской битвы раскрывает как подлинные масштабы трагедии народа и армии, так и глубину кардинальных самоизменений, произошедших в годы войны и позволивших нашим соотечественникам совершить великий подвиг Победы. Глубина и действенность проникновения идеологии и пропаганды в сознание участников войны, их роль в обеспечении победы над врагом должны оцениваться с учетом их взаимодействия с массовой и индивидуальной психологией. Представленная в статье попытка теоретико-методологического моделирования начавшихся под Сталинградом кардинальных изменений сознания и поведения воинов Красной Армии может способствовать дальнейшему, более полному и обстоятельному конкретноисторическому и междисциплинарному изучению психологических аспектов крупнейшей битвы Великой Отечественной войны, места и роли человеческого фактора в периоды военных конфликтов.

\section{СПИСОК ЛИТЕРАТУРЫ}

1. Адам, В. Трудное решение. Мемуары полковника 6-й германской армии / В. Адам. - М. : Прогресс, 1972.- 494 c.

2. Бирюкова, М. Война и мир отца Глеба / М. Бирюкова. - Электрон. текстовые дан. - Режим доступа: https://eparhia-saratov.ru/ (дата обращения: 07.07.2018). - Загл. с экрана.

3. Война день за днем... Беседа с писателем К. Симоновым // Песков В. Война и люди. - М. : Молодая гвардия, 1979. - С. 145-172.

4. Гареев, Махмуг. Уроки Сталинграда / Махмуг Гареев // Свободная мысль. - 1993. - № 1. - С. 79-90.

5. Драган, И. Г. Николай Крылов / И. Г. Драган. - М. : Молодая гвардия, 1988. -316 с.

6. Из опыта уличных боев / под ред. Ю. Костюк. - М. : Воениздат НКО СССР, 1943. - 38 c.

7. Исаев, А. В. Сталинград. За Волгой для нас земли нет / А. В. Исаев. - М. : Эксмо : Яуза, 2018. $544 \mathrm{c}$.

8. История России. XX век: 1939-2007 / под ред. А. Б. Зубова. - М. : Астрель : АСТ, 2009. - 847 с.

9. Куманев, Г. А. Некоторые итоги, последствия и уроки Сталинградской битвы (К 70-летию выдающейся победы на Волге) / Г. А. Куманев // Труды Института российской истории. Вып. 11. - М., 2013.C. $116-134$.

10. Максаков, В. «На мельницах войны»: историческая память о Сталинградской битве. Военная тактика и стратегии официальной памяти // Гефтер. - Электрон. текстовые дан. - Режим доступа: 
http://gefter.ru/archive/15598/ (дата обращения: 08.07.2018). - Загл. с экрана.

11. Мерцалов, А. Сталинградская битва. Полемические заметки / А. Мерцалов // Свободная мысль. - 1993. - № 1. - С. 91-102.

12. Назаретян, А. П. Агрессивная толпа, массовая паника, слухи. Лекции по социальной и политической психологии / А. П. Назаретян. - СПб. : Питер, 2003. - 192 с.

13. Каледа, В. Г. Записки рядового. Эскизы и зарисовки с натуры и по памяти / В. Г. Каледа. - М. : Изд-во Зачатьевского монастыря, 2007. - С. 219-234.

14. Сенявская, Е. С. Психология войны в ХХ веке. Исторический опыт России / Е. С. Сенявская. - М. : РОССПЭН, 1999. - $383 \mathrm{c}$.

15. Сенявская, Е. С. История войн России в человеческом измерении. Проблемы военно-исторической антропологии и психологии. Курс лекций / Е. С. Сенявская. - М. : РГГУ, 2012. - 332 с.

16. Сталинградская битва. Свидетельства участников и очевидцев. По материалам Комиссии по истории Великой Отечественной войны / под ред. Й. Хелльбек. - М. : Новое литературное обозрение, 2015. - 672 с. (Серия: Библиотека журнала «Неприкосновенный запас»).

17. Тиллих, П. Мужество быть / П. Тиллих // Избранное: Теология культуры. - М. : Юрист, 1995.-479с.

18. Уткин, А. И. Рузвельт / А. И. Уткин. - М. : Логос, 2000. - 544 с.

19. Философия вождизма. Хрестоматия по вождеведению / под ред. В. Б. Авдеева ; пер. с нем. А. М. Иванова. - М. : Белые айвы, 2006. -608 c.

20. Христофоров, В. С. Сталинград: Органы НКВД накануне и в дни сражения / В. С. Христофоров. - М. : Московские учебники и картолитография, 2008. -240 с.

21. Чуйков, В. И. Сражение века / В. И. Чуйков. М. : Советская Россия, 1975. -400 c.

\section{REFERENCES}

1. Adam V. Trudnoe reshenie. Memuary polkovnika 6-y germanskoy armii [Difficult Decision. Memoirs of the Colonel of the $6^{\text {th }}$ German Army]. Moscow, Progress Publ., 1972. 494 p.

2. Biryukova M. Voyna i mir ottsa Gleba [War and Piece of Father Gleb]. URL: https://eparhiasaratov.ru. (accessed 7 July 2018).

3. Voyna den za dnem... Beseda s pisatelem K. Simonovym [War Day by Day ... Conversation with Writer K. Simonov]. Peskov V. Voyna i lyudi [War and People]. Moscow, Molodaya gvardiya Publ., 1979, pp. 145-172.

4. Gareev Mahmut. Uroki Stalingrada [Lessons of Stalingrad]. Svobodnaya mysl, 1993, vol. 1, pp. 79-90.
5. Dragan I.G. Nikolay Krylov. Moscow, Molodaya gvardiya Publ., 1988. 316 p.

6. Kostyuk Yu., ed. Iz opyta ulichnykh boev [From the Experience of Urban Combats]. Moscow, Voenizdat NKO SSSR, 1943.38 p.

7. Isaev A.V. Stalingrad. Za Volgoy dlya nas zemli net [Stalingrad. For us There is no Land Beyond the Volga]. Moscow, Eksmo; Yauza Publ., 2018. 544 p.

8. Zubov A.B., ed. Istoriya Rossii. XX vek: 1939 2007 [History of Russia. The Twentieth Century: 19392007]. Moscow, Astrel; Ast Publ., 2009. 847 p.

9. Kumanev G.A. Nekotorye itogi, posledstviya i uroki Stalingradskoy bitvy (K 70-letiyu vydayushcheysya pobedy na Volge) [Some Results, Consequences and Lessons of the Battle of Stalingrad (To the $70^{\text {th }}$ Anniversary of the Outstanding Victory on the Volga)]. Trudy Instituta rossiyskoy istorii. Vyp. 11 [Proceedings of the Institute of Russian History of the Russian Academy of Sciences]. Moscow, 2013, iss. 11, pp. 116-134.

10. Maksakov V. «Na mel'nitsakh voyny»: istoricheskaya pamyat o Stalingradskoy bitve. Voennaya taktika i strategii ofitsialnoy pamyati ['On the Mills of War': Historical Memory of the Battle of Stalingrad. Military Tactics and Strategies of Official Memory]. Gefter. URL: http://gefter.ru/archive/15598/ (accessed 8 July 2018).

11. Mertsalov A. Stalingradskaya bitva. Polemicheskie zametki [The Stalingrad Battle. Polemic Notes]. Svobodnaya mysl, 1993, no. 1, pp. 91-102.

12. Nazaretyan A.P. Agressivnaya tolpa, massovaya panika, slukhi. Lektsii po sotsialnoy $i$ politicheskoy psikhologii [Aggressive Crowd, Mass Panic, Rumors. Lectures on Social and Political Psychology]. Saint Petersburg, Piter Publ., 2003. 192 p.

13. Kaleda V.G. Zapiski ryadovogo. Eskizy $i$ zarisovki s natury i po pamyati [Notes of a Private. Sketches and Drawings from Life and from Memory]. Moscow, Izd-vo Zachatyevskogo monastyrya, 2007, pp. 219-234.

14. Senyavskaya E.S. Psikhologiya voyny v XX veke. Istoricheskiy opyt Rossii [Psychology of War in the Twentieth Century. Historical Experience of Russia]. Moscow, ROSSPEN Publ., 1999. 383 p.

15. Senyavskaya E.S. Istoriya voyn Rossii v chelovecheskom izmerenii. Problemy voennoistoricheskoy antropologii i psikhologii. Kurs lektsiy [The History of Russian Wars in the Human Dimension. Problems of Military and Historical Anthropology and Psychology. Series of Lectures]. Moscow, RGGU Publ., 2012.332 p.

16. Hellbek J., ed. Stalingradskaya bitva. Svidetelstva uchastnikov $i$ ochevidtsev. Po materialam Komissii po istorii Velikoy Otechestvennoy voyny [The Stalingrad Battle. Evidence of Participants and Witnesses. According to the Materials of the Commission 


\section{ОТЕЧЕСТВЕННАЯ ИСТОРИЯ}

on the History of the Great Patriotic War]. Moscow, Novoe literaturnoe obozrenie Publ., 2015. 672 p. (Seriya: Biblioteka zhurnala «Neprikosnovennyy zapas»).

17. Tillih P. Muzhestvo byt [The Courage to Be]. Izbrannoe: Teologiya kultury [The Selected Works: Theology of Culture]. Moscow, Yurist Publ., 1995. $479 \mathrm{p}$.

18. Utkin A.I. Roosevelt. Moscow, Logos Publ., 2000.544 p.
19. Avdeev V.B., Ivanov A.M., eds. Filosofiya vozhdizma. Khrestomatiya po vozhdevedeniyu [Philosophy of Leaderism. Anthology of Leaderstudies]. Moscow, Belye ayvy Publ., 2006. 608 p.

20. Khristoforov V.S. Stalingrad: Organy NKVD nakanune $i v$ dni srazheniya [Stalingrad: the NKVD Before and During the Battle]. Moscow, Moskovskie uchebniki i kartolitografiya Publ., 2008. 240 p.

21. Chuykov V.I. Srazhenie veka [Battle of the Century]. Moscow, Sovetskaya Rossiya Publ., 1975. 400 p.

\section{Information about the Author}

Aleksandr L. Strizoe, Doctor of Sciences (Philosophy), Professor, Head of Department of Sociology, Volgograd State University, Prosp. Universitetsky, 100, 400062 Volgograd, Russian Federation, strizoe@volsu.ru,https://orcid.org/0000-0002-3241-0480

\section{Информация об авторе}

Стризое Александр Леонидович, доктор философских наук, профессор, заведующий кафедрой социологии, Волгоградский государственный университет, просп. Университетский, 100, 400062 г. Волгоград, Российская Федерация, strizoe@volsu.ru, https://orcid.org/0000-0002-3241-0480 